\title{
The use of palliative sedation: A comparison of attitudes of French-speaking physicians from Quebec and Switzerland
}

\author{
SERGE DUMONT, PH.D., ${ }^{1}$ DANIELLE BLONDEAU, PH.D., ${ }^{2}$ VÉRONIQUE TURCOTTE, M.SC., ${ }^{3}$ \\ GIAN DOMENICO BORASIO, M.D., DIP. PALL. MED., ${ }^{4}$ THIERRY CURRAT, M.A., ${ }^{4}$ \\ ROSE-ANNA FOLEY, PH.D., M.SC., ${ }^{4}$ AND MICHEL BEAUVERD, M.D. ${ }^{4}$ \\ ${ }^{1}$ School of Social Service, Laval University, Quebec City, Canada \\ ${ }^{2}$ Faculty of Nursing, Laval University, Quebec City, Canada \\ ${ }^{3}$ Laval University Cancer Research Centre, Quebec City, Canada \\ ${ }^{4}$ Palliative Care Service, Department of Medicine, Centre Hospitalier Universitaire Vaudois, Lausanne, Switzerland \\ (RECEIVED January 20, 2014; AcCEPTED March 7, 2014)
}

\begin{abstract}
Objective: Previous literature has suggested that laws and regulations may impact the use of palliative sedation. Our present study compares the attitudes of French-speaking physicians practicing in the Quebec and Swiss environments, where different laws are in place regarding physician-assisted suicide.

Method: Data were drawn from two prior studies, one by Blondeau and colleagues and another by Beauverd and coworkers, employing the same two-by-two experimental design with length of prognosis and type of suffering as independent variables. Both the effect of these variables and the effect of their interaction on Swiss and Quebec physicians' attitudes toward sedation were compared. The written comments of respondents were submitted to a qualitative content analysis and summarized in a comparative perspective.

Results: The analysis of variance showed that only the type of suffering had an effect on physicians' attitudes toward sedation. The results of the Wilcoxon test indicated that the attitudes of physicians from Quebec and Switzerland tended to be different for two vignettes: long-term prognosis with existential suffering $(p=0.0577)$ and short-term prognosis with physical suffering ( $p=0.0914)$. In both cases, the Swiss physicians were less prone to palliative sedation.

Significance of results: The attitudes of physicians from Quebec and Switzerland toward palliative sedation, particularly regarding prognosis and type of suffering, seem similar. However, the results suggest that physicians from Quebec could be slightly more open to palliative sedation, even though most were not in favor of this practice as an answer to end-of-life existential suffering.
\end{abstract}

KEYWORDS: Sedation, Laws, Regulations, End of life, Decision making

\section{INTRODUCTION}

\section{Sedation at the End of Life}

The use of sedation is increasingly accepted as an intervention of last resort to relieve intractable physical symptoms at the end of life. There is also a

Address correspondence and reprint requests to: Serge Dumont, School of Social Work, Pavillon Charles de Koninck, 1030, Avenue des Sciences Humaines, Laval University, Quebec, Quebec, Canada G1V 0A6. E-mail: Serge.Dumont@svs.ulaval.ca growing tendency, still controversial, to employ this intervention as a response to severe existential and/or psychological suffering (Claessens et al., 2008; Bruce \& Boston, 2011; Cherny, 2006; National Ethics Committee and Veterans Health Administration, 2006; Morita et al., 2002; Moynier-Vantieghem \& Beauverd, 2008; Chater et al., 1998; Seale, 2010).

Palliative sedation is defined here as a practice primarily intended to relieve refractory symptoms, that is, symptoms that cannot be suitably controlled through appropriate efforts with a tolerable 
intervention without compromising consciousness (Cherny \& Portenoy, 1994) in an imminently dying patient, as opposed to practices intended to deliberately shorten or end a patient's life (Bruce \& Boston, 2011; Rys et al., 2012). The nonstandardized terminology used in the literature (Claessens et al., 2008; Beel et al., 2002) and the inconsistency in the definition of sedation (Claessens et al., 2008; Chater et al., 1998; Beel et al., 2002; Braun et al., 2003; Cooney, 2005) have been widely documented. Variability in the use of sedation across countries is also reported (Claessens et al., 2008; Miccinesi et al., 2006; Fainsinger et al., 2000b; Anquinet et al., 2012), due likely to cultural differences (Fainsinger et al., 2000b; Anquinet et al., 2012; Fainsinger et al., 2000a), ethnicity (Curlin et al., 2008), or religious proscriptions (Seale, 2010; Curlin et al., 2008). The utilization of sedation also varies among clinicians (Cowan \& Walsh, 2001), which may be explained in part by the great difficulty involved in deciding on the use of sedation (Morita et al., 2002; Chater et al., 1998; González Barón et al., 2005) and the poor understanding of sedation as a means of controlling endof-life suffering (Seymour et al., 2007). Fear of hastening a patient's death and its legal implications may also deter its use (Rousseau, 2006). Previous studies have shown that some clinicians associate palliative sedation with a risk of shortening a patient's life (Morita et al., 2002), while others who had administered sedation more or less had the intention of hastening death (Seale, 2010; Rietjens et al., 2006; Douglas et al., 2008). However, this contrasts with the findings of other studies refuting the assumed life-shortening effect related to palliative sedation (Maltoni et al., 2009; Chiu et al., 2001; Muller-Busch et al., 2003; Morita et al., 1999; Sykes \& Thorns, 2003; Maltoni et al., 2012).

Sometimes perceived as a more acceptable practice than euthanasia (Seymour et al., 2007; Georges et al., 2008; Sercu et al., 2012) or physician-assisted suicide (Pomerantz et al., 2004; Raus et al., 2011), palliative sedation is often considered in the context of a patient's request for hastening death (Seale, 2010; Muller-Busch et al., 2003; Pomerantz et al., 2004; Rietjens et al., 2009; Chambaere et al., 2010; Raus et al., 2012; Blondeau et al., 2009). Rietjens and coworkers (2008) found that in $9 \%$ of cases continuous deep sedation was preceded by an unsuccessful request for euthanasia. Similarly, Blanker et al. (2012) reported that in $77 \%$ of cases euthanasia was discussed with the patient prior to the decision to employ continuous sedation. Some authors have suggested that in complex situations where patients ask for hastening of death, unskilled or emotionally exhausted physicians could apply sedation as an easy alternative to physician-assisted suicide or eu- thanasia (Morita et al., 2002; Billings \& Block, 1996; Quill \& Byock, 2000). Similar results were reported by Blanker and colleagues (2012), who showed that patients' requests for euthanasia coincided with a higher prevalence of pressure experienced by general practitioners to start continuous sedation, especially by those without previous experience of euthanasia.

In a study by Anquinet and colleagues (2012), the variability in the prevalence of continuous deep sedation appeared to reflect complex legal, cultural, social, and organizational factors more than differences in patients' characteristics or clinical profiles. Similarly, Rietjens et al. (2012) found that physicians' openness to discuss sedation with patients and relatives varies depending on local laws and ethics.

The present study focused on comparing the use of sedation in two different socio-jurisdictional environments: one where euthanasia and physician-assisted suicide are criminal practices (Quebec) and the other where physician-assisted suicide is tolerated and euthanasia prohibited (Switzerland).

\section{Objectives}

The aim of our study was to determine whether different attitudes toward palliative sedation could be observed between physicians from two socio-jurisdictional environments where pertinent laws and regulations differed. More precisely, it intended to compare the attitudes of French-speaking physicians from Quebec to those of French-speaking physicians from Switzerland.

\section{METHODS}

\section{Study Design and Measurement Instrument}

The target population consisted of physicians working in palliative care who had the ability to prescribe sedation in both the Province of Quebec and the French cantons of Switzerland. The data from Quebec were drawn from a study performed in 20022005 by Blondeau et al. (2005). The Swiss data were drawn from a replicated study performed in 2009-2011 by Beauverd et al. (2013) in the cantons of Vaud, Genève, Neuchâtel, Valais, and Jura. Respondents in Quebec practiced in palliative care homes, in hospitals with a palliative care unit or with beds for palliative care patients in various wards, or within in-home palliative care. In Switzerland, they practiced in palliative care units, on palliative care mobile teams, and in rehabilitation centers with palliative care beds.

The studies of Blondeau et al. (2005) and Beauverd et al. (2013) employed the same two-by-two 
experimental design, which manipulated two independent variables: length of prognosis and type of suffering. Four clinical vignettes were employed to measure the effect of these variables (see the Appendix). These vignettes consisted of sample situations presenting different combinations of variables. The measured dependent variable was the attitude toward the use of palliative sedation.

In order to control the independent variables, each respondent was assigned only one vignette. A definition of sedation was purposefully omitted in the questionnaire to avoid bias. The attitudes toward the use of palliative sedation were measured using a 6-point Likert-type scale, ranging from 1 (strongly disagree) to 6 (strongly agree). Respondents were then asked an open question inviting them to comment on their situation.

\section{Data Analysis}

Statistical analyses were performed with SAS 9.2 (Cary, North Carolina) software. Avariance analysis (unbalanced ANOVA) was performed by means of the general linear models (GLM) procedure. This analysis allowed measuring both the effect of the type of suffering and prognosis length, and the effect of their interaction on physicians' attitudes toward sedation. Attitudes toward sedation were then compared between the two jurisdictions for each vignette. A Wilcoxon test was then performed. This test was chosen because of the limited size of the subsample of respondents for each vignette.

The written comments were submitted to qualitative content analysis. Two members of the research team separately analyzed the content of all written comments and developed an open coding. Each unit of analysis (word, phrase, or paragraph) was given a code name and sorted into groups with related themes. This process was continued until all of the codes and categories were mutually exclusive and covered all variations. A comparative process of data analysis was then carried out. The two members met together to compare and discuss their coding.
Each point of divergence was debated and clarified until agreement on the set of codes was reached.

\section{RESULTS}

\section{Respondents}

The sample comprised 98 physicians from Quebec and 77 from Switzerland. The Quebec sample was $48 \%$ female. About $47 \%$ were $\leq 45$ years old, $41 \%$ were $46-55$ years old, and $11 \%$ were $\geq 56$ years old. About $31 \%$ had less than 6 years of experience in palliative care; $31 \%$ had between 6 and 10 years of experience, and $38 \%$ had more than 10 years of experience. The detailed results of the Quebec study were reported by Blondeau et al. (2005). The Swiss sample was $44 \%$ female. About $34 \%$ were $\leq 45$ years old, $31 \%$ were aged $46-55$ years old, and $33 \%$ were $\geq 56$ years old. About $29 \%$ had less than 6 years of experience in palliative care, $20 \%$ had between 6 and 10 years of experience, and $39 \%$ had more than 10 years of experience. The detailed results of the Swiss study were reported by Beauverd et al. (2013).

The analyses (chi-square test) indicated that the four subgroups from Quebec and the four subgroups from Switzerland (formed from the four clinical situations) were equivalent to each other in terms of sex and experience in palliative care $(p>0.05)$, but different in terms of age $(p<0.05)$. In Quebec, the number of subjects per vignette ranged from 19 to 28 , and in Switzerland from 15 to 25 (see Table 1).

\section{Physicians' Attitudes Toward Palliative Sedation}

The analysis of variance showed that only the type of suffering variable had an effect on physicians' attitudes toward sedation (Table 2). In fact, in both jurisdictions neither prognosis nor sociodemographic characteristics (sex, age, and years of experience in palliative care) influenced physicians' attitudes.

The results of the Wilcoxon test indicated that the attitudes of physicians from Quebec and Switzerland tended to be different for two vignettes: long-term

Table 1. Content of vignettes and respondents to each

\begin{tabular}{|c|c|c|c|c|}
\hline \multirow[b]{2}{*}{ Suffering } & \multicolumn{2}{|c|}{ Quebec } & \multicolumn{2}{|c|}{ Switzerland } \\
\hline & Existential & Physical & Existential & Physical \\
\hline \multicolumn{5}{|l|}{ Prognosis } \\
\hline Long term & $\begin{array}{l}\text { Vignette } 1 \\
n=21(25 \%)\end{array}$ & $\begin{array}{l}\text { Vignette } 2 \\
n=15(18 \%)\end{array}$ & $\begin{array}{l}\text { Vignette } 1 \\
n=17(22 \%)\end{array}$ & $\begin{array}{l}\text { Vignette } 2 \\
n=20(26 \%)\end{array}$ \\
\hline Short term & $\begin{array}{l}\text { Vignette } 4 \\
n=23(28 \%)\end{array}$ & $\begin{array}{l}\text { Vignette } 3 \\
n=24(29 \%)\end{array}$ & $\begin{array}{l}\text { Vignette } 4 \\
n=15(19 \%)\end{array}$ & $\begin{array}{l}\text { Vignette } 3 \\
n=25(32 \%)\end{array}$ \\
\hline
\end{tabular}


Table 2. Physicians' attitudes toward palliative sedation (mean \pm standard deviation)

\begin{tabular}{|c|c|c|c|c|}
\hline \multirow[b]{2}{*}{ Suffering* } & \multicolumn{2}{|c|}{ Quebec } & \multicolumn{2}{|c|}{ Switzerland } \\
\hline & Existential & $\overline{\text { Physical }}$ & $\overline{\text { Existential }}$ & Physical \\
\hline \multicolumn{5}{|l|}{ Prognosis $\dagger$} \\
\hline Long term & $2.65 \pm 1.57$ & $5.06 \pm 1.35$ & $1.88 \pm 1.54$ & $4.75 \pm 1.71$ \\
\hline Short term & $3.00 \pm 1.77$ & $5.29 \pm 1.01$ & $2.62 \pm 2.06$ & $4.54 \pm 1.67$ \\
\hline Model & \multicolumn{2}{|c|}{$F=21.95, d f=3, p<0.0001$} & \multicolumn{2}{|c|}{$F=12.34, d f=3, p<0.0001$} \\
\hline *Suffering & \multirow{2}{*}{\multicolumn{2}{|c|}{$\begin{array}{l}F=61.85, d f=1, p<0.0001 \\
F=0.93, d f=1, p=0.3361\end{array}$}} & \multicolumn{2}{|c|}{$F=33.92, d f=1, p<0.0001$} \\
\hline$\dagger$ Prognosis & & & $F=0.41, d f$ & 5259 \\
\hline Suffering and prognosis & \multicolumn{2}{|c|}{$F=0.04, d f=1, p=0.8461$} & \multicolumn{2}{|c|}{$F=1.31, d f=1, p=0.2567$} \\
\hline
\end{tabular}

prognosis with existential suffering $(p=0.0577)$ and short-term prognosis with physical suffering ( $p=$ 0.0914). In both cases, Swiss physicians were less prone to employ palliative sedation (Table 3).

\section{Written Comments}

Written comments from Quebec respondents $(n=$ 83/98) and Swiss respondents $(n=77 / 77)$ were summarized in a comparative perspective. The following contents highlight their main personal concerns.

A number of participants, mainly from Quebec, would agree that sedation is appropriate where the patient's prognosis is extremely guarded and physical suffering is intolerable and intractable. Some Quebec participants would consider it inhumane to allow someone to suffer without doing anything, writing that "ethically, it's the right thing to do" (translated). Other Quebec and Swiss participants would be more inclined to take recourse to sedation only after all other pain relief alternatives were ex-

Table 3. Comparison of the attitudes toward palliative sedation between the Quebec and Switzerland subgroups

\begin{tabular}{|c|c|c|c|}
\hline Vignette & Quebec & Switzerland & Wilcoxon \\
\hline \multicolumn{4}{|l|}{ Long-term } \\
\hline $\begin{array}{l}\text { existential } \\
\text { suffering }\end{array}$ & $\begin{array}{c}2.65 \pm 1.57 \\
n=26\end{array}$ & $\begin{array}{c}1.88 \pm 1.54 \\
n=17\end{array}$ & 0.0577 \\
\hline \multicolumn{4}{|l|}{ Long-term } \\
\hline $\begin{array}{l}\text { prognosis: } \\
\text { physical pain }\end{array}$ & $\begin{array}{c}5.06 \pm 1.35 \\
n=18\end{array}$ & $\begin{array}{c}4.75 \pm 1.71 \\
n=20\end{array}$ & 0.5730 \\
\hline \multicolumn{4}{|l|}{ Short-term } \\
\hline $\begin{array}{l}\text { prognosis: } \\
\text { existential } \\
\text { suffering }\end{array}$ & $\begin{array}{c}3.00 \pm 1.77 \\
n=26\end{array}$ & $\begin{array}{c}2.62 \pm 2.06 \\
n=13\end{array}$ & 0.3260 \\
\hline \multicolumn{4}{|l|}{ Short-term } \\
\hline $\begin{array}{l}\text { prognosis: } \\
\text { physical pain }\end{array}$ & $\begin{array}{c}5.29 \pm 1.01 \\
n=28\end{array}$ & $\begin{array}{c}4.54 \pm 1.67 \\
n=24\end{array}$ & 0.0914 \\
\hline
\end{tabular}

hausted. In the case of a long prognosis, however, one Quebec participant wondered if sedation to relieve physical suffering might become a kind of "legal active euthanasia" (translated), while one Swiss participant saw this as a proper situation for assisted suicide.

In the absence of intractable physical symptoms or uncontrolled pain, that is, only in the presence of "existential" suffering, close to half of the Quebec and Swiss participants did not see sedation as appropriate. Quebec participants noted that such suffering is very common at the end of life. As one participant put it, "If we prescribed terminal sedation for every patient who brought up [wanting to die], we'd be putting a lot of people to sleep" (translated). Other participants from Quebec and Switzerland disapproved of sedation for the relief of existential suffering where the patient's prognosis did not suggest impending death. Some participants, particularly from Quebec, saw the use of sedation in such conditions as unacceptable, unethical, or as a form of abandonment of the patient by the care team. Some participants, mainly from Quebec, also saw sedation for the relief of existential suffering as a form of euthanasia or assisted suicide. "It still bothers me for a prognosis of one or two months" (translated), wrote one Quebec participant. "The patient looks on death as deliverance, which for me blurs the line between sedation and euthanasia" (translated). In such cases, Swiss participants would be more inclined to discuss assisted suicide with the patient. For them, it was inappropriate to propose sedation to patients who want to die.

Some Quebec and Swiss participants were more open to sedation in the case of existential suffering, however. One Swiss participant expressed these views by describing sedation as a "good alternative to assisted suicide and something families might be more likely to accept" (translated), while another Swiss participant felt that "sedation is an acceptable response because its first goal as a treatment is to relieve an intractable symptom, not to affect life 
expectancy" (translated). There were also some Quebec participants who saw existential suffering as equivalent to physical suffering and should therefore be considered in the same way.

Both Quebec and Swiss participants felt it was important to discuss and clarify what the patient wanted before considering sedation. As one Swiss participant put it, "A loss of meaning doesn't mean you need to be put to sleep. And did the patient ask for it?" (translated). Some participants, mainly from Quebec, were more inclined toward sedation if it was clear that this was what the patient wanted. One Quebec participant wrote, "If the patient 'clearly' asks for it, I think not providing end-of-life sedation would be unethical" (translated). A number of participants, mainly from Quebec, were more favorable to sedation if the patient was able to consent to it and had done so. As one Quebec participant put it, "I think it's okay to prescribe sedation but not to impose it" (translated). Quebec and Swiss participants emphasized the importance of involving loved ones in the process. Some participants, mainly from Quebec, noted that consent from the patient's family should be obtained before sedation was initiated.

\section{DISCUSSION}

Our study results suggest that the attitudes of the participating physicians from Quebec and Switzerland toward palliative sedation, particularly regarding prognosis and type of suffering, were similar, despite the different legislations in place regarding physician-assisted suicide in their respective environments of practice. The group from Quebec did reach higher means on the Likert scale than did the group from Switzerland for all vignettes, which could suggest that respondents from Quebec would be more open to palliative sedation than respondents from Switzerland seemed to be, even though the majority were not in favor of sedation as an answer to end-of-life existential suffering.

Faced with a request for a "hastened-death," some respondents from Switzerland would suggest considering physician-assisted suicide instead of palliative sedation. This could mean that in Switzerland there is a need to distinguish palliative sedation and physician-assisted suicide. A study by Raus and colleagues (2011) demonstrated that physician-assisted suicide and palliative sedation are usually applied to different groups of patients. Physician-assisted suicide is usually requested by terminal patients who value control during the dying process and who feel that their disease has harmed or threatens to harm their dignity, while palliative sedation is employed predominantly for patients who want to avoid pain and suffering (Raus et al., 2011). Different re- sults were reported by Seale (2010), who found that palliative sedation was associated with a higher rate of requests from patients or relatives for a hastened death. In the same way, the physicians who were in favor of assisted suicide legislation were more likely to report using palliative sedation. As this study was performed in the United Kingdom, where physician-assisted suicide and euthanasia are a criminal offence, this could suggest that palliative sedation is sometime used in response to requests for a hastened death when physicianassisted suicide or euthanasia is not an option.

Some respondents from Quebec would be in favor of sedation for a patient experiencing severe psychological or existential suffering if the prognosis was limited. These respondents mentioned that psychological or existential suffering should be given the same consideration as physical pain. Intractable psychological distress is sometimes the reason given by physicians for starting palliative sedation (Seale, 2010), while others consider its use in such a situation as a death-hastening measure to be tantamount to physician-assisted suicide or euthanasia (Beel et al., 2002). In the current study, some respondents from both Quebec and Switzerland would equate using sedation in the presence of existential suffering with a form of euthanasia, particularly if the patient's prognosis was longer.

Naturally, the desire for a hastened death depends on numerous factors. This desire may fluctuate over time (Goelitz, 2003) and may be influenced by interventions made by palliative care clinicians (Seale, 2010; Goelitz, 2003). As well, prior studies have revealed concerns about patients requesting a hastened death in order to avoid being a burden to others (Lee et al., 1996; Cavalieri et al., 2002) or when they felt familial, institutional, or social pressures (Battin, 2008). In a study by Blanker et al. (2012), general practitioners more often experienced pressure from patients and their relatives to start continuous sedation until death when patients had a longer prognosis and showed psychological symptoms as compared to a shorter prognosis and physical symptoms only.

It is often recommended that initiating palliative sedation should be the result of a rigorous decisionmaking process involving an interdisciplinary team, the patient, and his loved ones (Moynier-Vantieghem \& Beauverd, 2008; de Graeff \& Dean, 2007; Goncalves et al., 2012). Few of our respondents mentioned that the decision to use sedation should be discussed with the care team. However, more respondents considered that the utilization of sedation should be discussed with patient and family. Some respondents from both groups highlighted the importance of clarifying a patient's desires, and would 
agree to initiate sedation if this was congruent with those desires. Similarly, obtaining the patient's agreement was also cited in both groups as a criterion that should be met, which is in line with prior studies (Claessens et al., 2008; Braun et al., 2003).

\section{LIMITATIONS}

Some of the limitations of our study include the years separating the two studies (2004-2005 and 2009$2011)$, the limited response rates in both $(36 \%$ in Switzerland and $42 \%$ in Quebec), and the study population being restricted to physicians. Potential confounding effects that could explain some differences observed between the two groups were not controlled, such as physicians' age and level of religious faith. To facilitate interpretation of the results and their analyses, the concepts of physical suffering and existential suffering were separated in the vignettes, which is rarely the case in daily clinical practice. Another limitation concerns the fact that only two independent variables were investigated in our study: length of prognosis and type of suffering. Last, respondents were invited to comment about their position only with respect to their specific vignette, which may limit the generalizability of these testimonies, despite their richness and relevance.

\section{CONCLUSION}

The attitudes of physicians from Quebec and Switzerland toward palliative sedation, particularly regarding prognosis and type of suffering, seem similar, despite the different legislation in place regarding physician-assisted suicide in each practice environment. However, the results suggest that physicians from Quebec could be slightly more open to palliative sedation, even though the majority were not in favor of this practice as an answer to end-of-life existential suffering. In a context where physician-assisted suicide is authorized, it is possible that physicians are more inclined to favor physicianassisted suicide over palliative sedation when patients experience existential suffering, particularly if their prognosis is more extended.

\section{ACKNOWLEDGMENTS}

We gratefully thank all the participating physicians at both study sites. We also are grateful to Stéphane Turcotte, biostatistician, for the quantitative analyses, and Sandy Lavoie, research assistant, who contributed to the qualitative analyses. We also thank the institutions that granted funds: the Chaire de soins palliatifs of Laval University in Quebec and the Social Sciences and Humanities Research Council of Canada.

\section{REFERENCES}

Anquinet, L., Rietjens, J.A., Seale, C., et al. (2012). The practice of continuous deep sedation until death in Flanders (Belgium), the Netherlands, and the U.K.: A comparative study. Journal of Pain and Symptom Management, 44(1), 33-43.

Battin, M.P. (2008). Terminal sedation: Pulling the sheet over our eyes. Hastings Center Report, 38(5), 27-30.

Beauverd, M., Bernard, M., Currat, T., et al. (2013). French Swiss physicians' attitude toward palliative sedation: Influence of prognosis and type of suffering. Palliative \& Supportive Care, June 17, 1-6. Epub ahead of print.

Beel, A., McClement, S.E. \& Harlos, M. (2002). Palliative sedation therapy: A review of definitions and usage. International Journal of Palliative Nursing, 8(4), 190-199.

Billings, J.A. \& Block, S.D. (1996). Slow euthanasia. Journal of Palliative Care, 12(4), 21-30.

Blanker, M.H., Koerhuis-Roessink, M., Swart, S.J., et al. (2012). Pressure during decision making of continuous sedation in end-of-life situations in Dutch general practice. BMC Family Practice, 13, 68.

Blondeau, D., Roy, L., Dumont, S., et al. (2005). Physicians' and pharmacists' attitudes toward the use of sedation at the end of life: Influence of prognosis and type of suffering. Journal of Palliative Care, 21(4), 238-245.

Blondeau, D., Dumont, S., Roy, L., et al. (2009). Attitudes of Quebec doctors toward sedation at the end of life: An exploratory study. Palliative \& Supportive Care, 7(3), 331-337.

Braun, T.C., Hagen, N.A. \& Clark, T. (2003). Development of a clinical practice guideline for palliative sedation. Journal of Palliative Medicine, 6(3), 345-350.

Bruce, A. \& Boston, P. (2011). Relieving existential suffering through palliative sedation: Discussion of an uneasy practice. Journal of Advanced Nursing, 67(12), 2732-2740.

Cavalieri, T.A., Pomerantz, S.C., Ciesielski, J., et al. (2002). Attitudes of osteopathic physicians toward physicianassisted suicide. Journal of the American Osteopathic Association, 102(1), 27-34.

Chambaere, K., Bilsen, J., Cohen, J., et al. (2010). Continuous deep sedation until death in Belgium: A nationwide survey. Archives of Internal Medicine, 170(5), 490-493.

Chater, S., Viola, R., Paterson, J., et al. (1998). Sedation for intractable distress in the dying: A survey of experts. Palliative Medicine, 12(4), 255-269.

Cherny, N.I. (2006). Sedation for the care of patients with advanced cancer. Nature Clinical Practice. Oncology, 3(9), 492-500.

Cherny, N.I. \& Portenoy, R.K. (1994). Sedation in the management of refractory symptoms: Guidelines for evaluation and treatment. Journal of Palliative Care, 10(2), $31-38$.

Chiu, T.Y., Hu, W.Y., Lue, B.H., et al. (2001). Sedation for refractory symptoms of terminal cancer patients in Taiwan. Journal of Pain and Symptom Management, 21(6), 467-472.

Claessens, P., Menten, J., Schotsmans, P., et al. (2008). Palliative sedation: A review of the research literature. Journal of Pain and Symptom Management, 36(3), 310-333.

Cooney, G.A. (2005). Palliative sedation: The ethical controversy. Available from http://www.medscape.com/viewarticle/499472.

Cowan, J.D. \& Walsh, D. (2001). Terminal sedation in palliative medicine: Definition and review of the literature. Supportive Care in Cancer, 9(6), 403-407. 
Curlin, F.A., Nwodim, C., Vance, J.L., et al. (2008). To die, to sleep: US physicians' religious and other objections to physician-assisted suicide, terminal sedation, and withdrawal of life support. The American Journal of Hospice \& Palliative Care, 25(2), 112-120.

de Graeff, A. \& Dean, M. (2007). Palliative sedation therapy in the last weeks of life: A literature review and recommendations for standards. Journal of Palliative Medicine, 10(1), 67-85.

Douglas, C., Kerridge, I. \& Ankeny, R. (2008). Managing intentions: The end-of-life administration of analgesics and sedatives, and the possibility of slow euthanasia. Bioethics, 22(7), 388-396.

Fainsinger, R.L., de Moissac, D., Mancini, I., et al. (2000a). Sedation for delirium and other symptoms in terminally ill patients in Edmonton. Journal of Palliative Care, 16(2), 5-10.

Fainsinger, R.L., Waller, A., Bercovici, M., et al. (2000b). A multicentre international study of sedation for uncontrolled symptoms in terminally ill patients. Palliative Medicine, 14(4), 257-265.

Georges, J.J., The, A.M., Onwuteaka-Philipsen, B.D., et al. (2008). Dealing with requests for euthanasia: A qualitative study investigating the experience of general practitioners. Journal of Medical Ethics, 34(3), $150-155$.

Goelitz, A. (2003). Suicidal ideation at end-of-life: The palliative care team's role. Palliative \& Supportive Care, 1(3), 275-278.

Goncalves, F., Cordero, A., Almeida, A., et al. (2012). A survey of the sedation practice of Portuguese palliative care teams. Supportive Care in Cancer, 20(12), 3123-3127.

González Barón, M., Gomez Raposo, C. \& Pinto Marin, A. (2005). Sedation in clinical oncology. Clinical \& Translational Oncology, 7(7), 295-301.

Lee, M.A., Nelson, H.D., Tilden, V.P., et al. (1996). Legalizing assisted suicide: Views of physicians in Oregon. The New England Journal of Medicine, 334(5), 310-315.

Maltoni, M., Pittureri, C., Scarpi, E., et al. (2009). Palliative sedation therapy does not hasten death: Results from a prospective multicenter study. Annals of Oncology, 20(7), 1163-1169.

Maltoni, M., Scarpi, E., Rosati, M., et al. (2012). Palliative sedation in end-of-life care and survival: A systematic review. Journal of Clinical Oncology, 30(12), 1378-1383.

Miccinesi, G., Rietjens, J.A., Deliens, L., et al. (2006). Continuous deep sedation: Physicians' experiences in six European countries. Journal of Pain and Symptom Management, 31(2), 122-129.

Morita, T., Tsunoda, J., Inoue, S., et al. (1999). Do hospice clinicians sedate patients intending to hasten death? Journal of Palliative Care, 15(3), 20-23.

Morita, T., Akechi, T., Sugawara, Y., et al. (2002). Practices and attitudes of Japanese oncologists and palliative care physicians concerning terminal sedation: A nationwide survey. Journal of Clinical Oncology, 20(3), 758-764.

Moynier-Vantieghem, K. \& Beauverd, M. (2008). Clinical and practical aspects of palliative sedation [in French]. Revue Medicale Suisse, 4(145), 462-466.

Muller-Busch, H.C., Andres, I. \& Jehser, T. (2003). Sedation in palliative care: A critical analysis of 7 years experience. BMC Palliative Care, 2(1), 2.

National Ethics Committee and Veterans Health Administration (2006). The ethics of palliative sedation as a therapy of last resort. The American Journal of Hospice \& Palliative Care, 23(6), 483-491.
Pomerantz, S.C., Bhatt, H., Brodsky, N.L., et al. (2004). Physicians' practices related to the use of terminal sedation: Moral and ethical concerns. Palliative \& Supportive Care, 2(1), 15-21.

Quill, T.E. \& Byock, I.R. (2000). Responding to intractable terminal suffering: The role of terminal sedation and voluntary refusal of food and fluids. ACP-ASIM Endof-Life Care Consensus Panel. American College of Physicians-American Society of Internal Medicine. Annals of Internal Medicine, 132(5), 408-414.

Raus, K., Sterckx, S. \& Mortier, F. (2011). Is continuous sedation at the end of life an ethically preferable alternative to physician-assisted suicide? The American Journal of Bioethics, 11(6), 32-40.

Raus, K., Anquinet, L., Rietjens, J., et al. (2012). Factors that facilitate or constrain the use of continuous sedation at the end of life by physicians and nurses in Belgium: Results from a focus group study. Journal of Medical Ethics, 40(4), 230-234.

Rietjens, J.A., van Delden, J.J., van der Heide, A., et al. (2006). Terminal sedation and euthanasia: A comparison of clinical practices. Archives of Internal Medicine, 166(7), 749-753.

Rietjens, J., van Delden, J., Onwuteaka-Philipsen, B., et al. (2008). Continuous deep sedation for patients nearing death in The Netherlands: Descriptive study. BMJ, 336(7648), 810-813.

Rietjens, J.A., Buiting, H.M., Pasman, H.R., et al. (2009). Deciding about continuous deep sedation: Physicians' perspectives. A focus group study. Palliative Medicine, 23(5), 410-417.

Rietjens, J.A., Voorhees, J.R., van der Heide, A., et al. (2012). Approaches to suffering at the end of life: The use of sedation in the USA and Netherlands. Journal of Medical Ethics, 40(4), 235-240.

Rousseau, P.C. (2006). Palliative sedation and the fear of legal ramifications. Journal of Palliative Medicine, $9(2), 246-247$.

Rys, S., Deschepper, R., Mortier, F., et al. (2012). The moral difference or equivalence between continuous sedation until death and physician-assisted death: Word games or war games? A qualitative content analysis of opinion pieces in the indexed medical and nursing literature. Journal of Bioethical Inquiry, 9(2), 171-183.

Seale, C. (2010). Continuous deep sedation in medical practice: A descriptive study. Journal of Pain and Symptom Management, 39(1), 44-53.

Sercu, M., Pype, P., Christiaens, T., et al. (2012). Are general practitioners prepared to end life on request in a country where euthanasia is legalised? Journal of Medical Ethics, 38(5), 274-280.

Seymour, J.E., Janssens, R. \& Broeckaert, B. (2007). Relieving suffering at the end of life: practitioners' perspectives on palliative sedation from three European countries. Social Science \& Medicine, 64(8), 1679-1691.

Sykes, N. \& Thorns, A. (2003). Sedative use in the last week of life and the implications for end-of-life decision making. Archives of Internal Medicine, 163(3), 341-344.

\section{APPENDIX. CLINICAL VIGNETTES}

\section{Clinical Vignette No. 1: Robert}

Robert Casey has been married to Jane for 36 years. They have two married sons and three granddaughters. He 
retired two years ago, two months before being diagnosed with colorectal cancer (carcinoma). At that time, staging did not indicate any spread of the tumor. He underwent a left hemicolectomy with a colostomy. Resection margins were clear, but 3 out of 10 ganglia were positive.

Some 15 months later, a recurrence was discovered in the true pelvis. Examination showed a $3 \times 5 \mathrm{~cm}$ mass in the true pelvis, retroperitoneal ganglionic damage, and two hepatic metastases ( 4 and $2.5 \mathrm{~cm}$ ). Robert underwent chemotherapy, which was terminated after six cycles because the illness was progressing.

Some 18 days ago, Robert was admitted to hospital in the palliative care unit. His state of health is deteriorating progressively. There is one major problem: the pain is not subsiding despite multiple attempts to alleviate it. The abdominal pain is diffuse, described as shooting with a sensation of heaviness, and very sharp frequent exacerbations in the form of stabbing pain that reaches an intensity of 10 out of 10 on the visual scale.

Examination shows that Robert has lost weight and is jaundiced and very weak. His abdomen has increased in volume with moderate ascites. The hepatic lobe is painful to palpation, and the liver is greater in volume and filled with hard nodules. A recent investigation does not show any lesion of the bone structure.

Multiple attempts to alleviate his pain have failed to provide acceptable comfort for the patient. Robert is currently on the following medications:

- hydromorphone $5 \mathrm{mg} / \mathrm{h}$ continuous subcutaneous drip and breakthrough doses every 30 minutes if needed

- gabapentin $400 \mathrm{mg}, 1$ capsule, 4 times daily

- dexamethasone $4 \mathrm{mg}$, subcutaneous, 4 times daily

- naproxen $500 \mathrm{mg}, 1$ tablet, twice daily

- ketamine $8 \mathrm{mg} / \mathrm{h}$ continuous subcutaneous drip

- amitryptiline $50 \mathrm{mg}, 1$ tablet at bedtime

- clonazepam $0.5 \mathrm{mg}, 1$ tablet lid, and $2 \mathrm{mg}, 1$ tablet at bedtime

- haloperidol $1 \mathrm{mg}, 1$ tablet, twice daily

- laxatives (emollient and stimulant), bowel movements are regular

Note. Methadone was tried but brought about major intolerable side effects; antiarrhythmics did not provide relief.

Given the patient's state and considering how quickly he is deteriorating, one can estimate a prognosis of no longer than 5 to 10 days.

Robert is constantly in pain and rests only for short periods of time. He has received 10 breakthrough doses within the last 24 hours despite the fact that his medication had been readjusted.

\section{Clinical Vignette No. 2: Claire}

Claire Germain is a 55-year-old lawyer and divorcee with no children. However, her family network is large, and she has many friends. Ovarian cancer (mucinous carci- noma) was diagnosed 15 months ago. She underwent surgeries: hysterectomy, oophorectomy, bilateral salpingectomy, and cytoreduction of neoplastic implants found at the peritoneal level. Last year, the cancer progressed in spite of many cycles of different types of chemotherapy.

Claire has therefore been admitted to the palliative care unit because the situation at home was becoming too trying. She has multiple hepatic metastases and major peritoneal carcinomatosis with no intestinal obstruction. She also presents large ascites that were tapped twice in the past 10 days. She suffers from diffuse pain in the abdomen and the right lower part of the thorax. Analgesic medication makes her comfortable.

Examination shows that the patient has lost weight but is not jaundiced. She is lucid but has slower motor skills. She needs help with all her activities. Pulmonary auscultation shows a decreased vesicular murmur by one third on the lower right, which is evidence of pleural effusion. The patient is not, however, dyspneic. The abdomen has been supple since the last ascites puncture; the multiple hepatic and peritoneal nodules can be felt. Claire is on the following medications:

- fentanyl $50 \mu \mathrm{g} / \mathrm{h}, 1$ patch every 3 days

- hydromorphone $1 \mathrm{mg}$ subcutaneously, every $30 \mathrm{~min}-$ utes if in pain (she takes 1 breakthrough (dose every 2 days)

- naproxen $375 \mathrm{mg}, 1$ tablet twice daily

- lorazepam $1 \mathrm{mg}, 1$ tablet at bedtime

- laxatives (bowel movement every 2 to 3 days)

She is deteriorating quickly, and one can reasonably assume that the prognosis is less than 10 days.

Physical pain is well alleviated and the patient feels comfortable; however, she requires help with all her activities. She is grateful for the help given, but Claire says she can no longer stand this deterioration, which she finds degrading. Despite the psychosocial support she receives from the social worker and the joint follow-up by her physician, she constantly repeats that her life no longer "makes sense."

\section{Clinical Vignette No. 3: Jim}

Jim Foster is a retired civil engineer. Twice divorced, he has been living with the same woman for the past 14 years. He has two daughters (37 and 47 years old) from his first marriage and one son (30 years old) from his second. He gets on well with them, but they all live abroad. For the past 12 years, he has been suffering from prostate cancer.

Over the years, he has been treated in the usual manner for this condition: prostatectomy, hormone therapy, chemotherapy, and radiotherapy. He has also taken part in clinical trials during the past two years and has gone across the border for a second opinion. However, the illness is out of control. The last staging showed multiple osseous metastases, as well as major liver and ganglionic damage.

At his request, Jim has been hospitalized to lessen the burden on the woman he lives with. Being younger than 
him, she works full time. Since his state of health has deteriorated, the patient needs a great deal of help with his daily care and to just move around. He is fed up with being dependent. His medications are as follows:

- morphine-LA $60 \mathrm{mg}, 1$ tablet twice daily

- morphine $10 \mathrm{mg}, 1$ tablet every hour if needed

- rofecoxib $25 \mathrm{mg}, 1$ tablet twice daily

- zoledronate $8 \mathrm{mg}$, IV every month

- biculatamide $50 \mathrm{mg}, 1$ tablet daily

- goselerine $10.8 \mathrm{mg}$, subcutaneously every 3 months

- omeprasole $20 \mathrm{mg}, 1$ tablet daily

- lorazepam mg, 1 tablet at bedtime

- acebutolol $200 \mathrm{mg}, 1$ tablet daily

- amlodipine $10 \mathrm{mg}, 1$ tablet daily

- isosorbide extended release $60 \mathrm{mg}, 1$ tablet daily

- acetylsalicylic acid $325 \mathrm{mg}, 1$ tablet daily

- lisinopril $20 \mathrm{mg}, 1$ tablet daily

This medication usually relieves his pain. From the way his condition is changing, one can estimate his prognosis at one to two months.

Jim constantly expresses his wish to die. Since his life has no more meaning for him, he sees death as a release. He mentions that his next of kin are aware of his wishes. As for himself, he has nothing to expect from life in this state of dependence on others. According to the psychiatrist and the social worker, Jim shows no signs of depression and is able to make decisions for himself.

\section{Clinical Vignette No. 4: Julian}

Julian Davis is a 60-year-old painter who has traveled the world. He suffers from recurrent epidermoid carcinoma located in the right oropharynx. Three years ago, he underwent surgery and radiotherapy. Recurrence of the disease was diagnosed six months ago. Because the tumor could not be treated surgically, radiotherapy and chemotherapy were indicated. The initial response was positive, but even- tually the lesion continued developing. It has now spread to the right side of the neck, but there is no skin ulceration.

The patient complains of shooting pain, a burning feeling, and neuralgia on the right side of the cervix, with pain spreading toward the right ear. This pain is rated at 9-10/10 and drops to 8/10 for short periods following breakthrough doses. Medications are as follows:

- fentanyl $250 \mu \mathrm{g} / \mathrm{h}$ patches

- morphine $20 \mathrm{mg}$, subcutaneously every 30 minutes if any discomfort

- methotrimeprazine $15 \mathrm{mg}$, subcutaneously 4 times daily

- sodium naproxen $500 \mathrm{mg}$, twice daily

- dexamethasone $4 \mathrm{mg}$, subcutaneously 4 times daily

- clonazepam $1 \mathrm{mg}, 4$ times daily

- gabapentin $800 \mathrm{mg}, 1$ capsule 4 times daily

- flecainide $100 \mathrm{mg}, 1.5$ tablets twice daily

- omeprasole $20 \mathrm{mg}, 1$ tablet daily

- laxatives

- olanzapine $7.5 \mathrm{mg}$ regularly at bedtime and $5 \mathrm{mg} 3$ times daily if confused or agitated

The pain has not subsided, despite multiple attempts to alleviate symptoms, and Julian experiences constant discomfort. The pain is never under the $8 / 10$ level, which he finds unbearable. Any increase in analgesic medication is hampered because of major side effects, such as cognitive impairment and agitation. Methadone, ketamine, clonidine, and topiramate have been tried without results or, worse, with unbearable side effects.

The patient was admitted to the palliative care unit many weeks ago. He is progressively deteriorating, losing weight, and becoming increasingly tired. The professionals who care for him think his prognosis is between four and eight weeks.

Julian repeats over and over again that he cannot bear the situation any longer. He is obsessed with the discomfort and pain, which have taken over his whole life. He asks you to do something. 